\title{
Autonomy and the Patient with Right Hemisphere Cognitive-Communication Deficits: Ethical Considerations in Rehabilitation Practice
}

\author{
Leora R. Cherney, Ph.D., CCC-SLP, BC-ANCDS, FACRM, ${ }^{1,2}$ \\ Laura Kinsey, M.S., CCC-SLP, ${ }^{1}$ and Elissa Larkin Conlon, M.S., CCC-SLP ${ }^{1}$
}

\section{ABSTRACT}

Clinicians must often contend with ethical issues that arise during rehabilitation. When a patient has right hemisphere damage (RHD), these concerns may be exacerbated because of the presence of cognitive deficits. In this article, we focus on the ethical principle of respect for autonomy, which raises issues relevant to patients with RHD who have impaired executive control functions. Respect for autonomy involves respecting others in terms of their decision-making and subsequent actions. Disagreements may occur between members of the rehabilitation team, the patient, and family about the decisions that the patient makes. Clinicians may have concerns about the patient's capacity to make informed decisions. Indeed, in some cases, because the patient is "talking," the verbal skills may mask the impairments in underlying cognitive processes. We provide two case examples of patients with RHD with sufficient language skills to express their choices, but cognitive deficits that affect their decision-making abilities. We use a clinical decision-making model adapted from Jonsen et al to discuss the cases. In both cases, the rehabilitation team strives to balance what they deem to be in the best interest of the patient while continuing to respect the patient's autonomy.

KEYWORDS: autonomy, right hemisphere stroke, executive function, decisional capacity, cognition

${ }^{1}$ Think and SpeakLab, Shirley Ryan AbilityLab, Chicago, Illinois; ${ }^{2}$ Department of Physical Medicine and Rehabilitation, Department of Communication Sciences and Disorders, Northwestern University, Chicago, Illinois.

Address for correspondence: Leora R. Cherney, Ph.D., CCC-SLP, BC-ANCDS, FACRM, Think and Speak Lab, Shirley Ryan AbilityLab, 25th floor, 355 East Erie Street, Chicago, IL 60611 (e-mail: Lcherney@sralab.org).
Moral and Ethical Considerations When Caring for Adults; Guest Editor, Jennifer Horner, Ph.D., J.D.

Semin Speech Lang 2020;41:232-240. Copyright (C) 2020 by Thieme Medical Publishers, Inc., 333 Seventh Avenue, New York, NY 10001, USA. Tel: +1(212) 7600888.

DOI: https://doi.org/10.1055/s-0040-1710324.

ISSN 0734-0478. 
Learning Outcomes: As a result of this activity, the reader will be able to (1) describe the heterogeneity of the RHD population; (2) differentiate decisional and executive autonomy; (3) discuss how a clinical decisionmaking model can be used in inpatient and outpatient rehabilitation; (4) describe two examples of balancing beneficence and respect for autonomy in patients with RHD.

Individuals with damage to the right hemisphere typically present with a cluster of cognitive deficits that may include impairments in the areas of attention, perception, memory, and executive functioning. ${ }^{1-3}$ The impact of these cognitive deficits may be evident during functional daily activities as well as in the performance of more complex or novel tasks. In addition, unilateral left neglect and anosognosia, a decreased awareness of the presence of deficits or the extent to which these deficits affect daily functioning, are considered to be hallmark features of right hemisphere stroke.

However, patients with right hemisphere damage (RHD) are heterogeneous with regard to the presence and severity of these cognitive deficits and their manifestations. Some cognitive areas may be more or less impaired, while others may be within the normal range as compared with the person's premorbid function. Despite the lack of a stereotypical profile of patients with RHD, there is general agreement that rehabilitation outcomes, including length of stay, functional status at discharge, and discharge placement, are negatively impacted by the presence and severity of cognitive deficits, unilateral neglect, and anosognosia. ${ }^{3,4}$

The heterogeneity in presentation of symptoms in patients with RHD extends to communication as well. Most often, patients with RHD are "talking," but may demonstrate deficits in pragmatics, discourse comprehension and production, and impaired prosody that vary in severity within and across individuals. ${ }^{2,3,5}$ While there is no one explanation for the cause of these communication symptoms and patterns, it is generally recognized that underlying cognitive deficits contribute to their manifestation.

The management of patients with RHD can be challenging for clinicians, and many ethical issues can arise during the rehabilitation process. As with any patient population in rehabilitation, clinicians need to be aware of the basic principles of bioethics that include respect for the person's autonomy, benevolence (do good), non-maleficence (do no harm), and justice (equal treatment regardless of social, financial, sexual, or cultural factors). ${ }^{6}$ Importantly, rehabilitation differs from the traditional medical model because it emphasizes the patients' active participation in decision-making, the team approach to care, and the long-term nature of the rehabilitation process that facilitates stronger relationships between patients, families, and rehabilitation clinicians. ${ }^{6-8}$ These differences have prompted increased discussion of the ethical issues and challenges that are unique to the rehabilitation setting., ${ }^{6,7,9-11}$ We have previously addressed ethical issues that might arise in relation to lack of awareness of patients with RHD and decisions regarding whether or not to provide treatment to patients with anosognosia. ${ }^{12}$ In this article, we focus on situations involving patients with RHD and impaired executive control in which ethical concerns arise involving respect for autonomy.

Autonomy has been defined as the "capacity to think, decide, and act on the basis of such thought and decision, freely and independently, without hindrance." ${ }^{13}$ Within rehabilitation, Hunt and Ells have identified two important aspects of autonomy. ${ }^{14}$ The first refers to physical aspects including functional independence and the ability for self-care, whereas the second refers to the person's cognitive abilities to make informed and intentional choices related to their own values, preferences, and life goals without any outside influences. ${ }^{15}$ Respect for autonomy involves respecting the self-determination of others in terms of their decision-making and subsequent actions. Issues arise when there are disagreements among members of the rehabilitation team, the patient, and family about the decisions that the patient makes. In the case of patients with RHD, clinicians may have concerns about the patient's capacity to make informed decisions because of the presence of cognitive deficits. Indeed, in some cases, because the patient is "talking," the verbal skills may mask the impairments in underlying cognitive 
processes. Conflict may also arise when there are differences in the values of the patients and the clinical team.

Collopy ${ }^{16}$ and $\mathrm{McCullough}$ et $\mathrm{al}^{17}$ have offered a more comprehensive conceptualization of patient autonomy by highlighting the importance of considering executive control functions which include judgment, planning, and problem solving. They make a distinction between decisional autonomy, the process of making decisions for oneself or delegating that power to someone else, versus executive autonomy, which is the process of actually carrying out one's decisions into effect. This distinction is an important one when considering individuals with cognitivecommunicative deficits associated with RHD. Some patients with RHD may not have either decisional or executive autonomy. However, others may be verbal with sufficient memory skills and other nonexecutive cognitive skills for decisional autonomy but not for executive autonomy. Because of impairments in executive functions, they may not have the ability to make, adapt, and implement plans. Furthermore, the presence of a physical impairment (such as left hemiparesis) in combination with poor awareness or underestimation of that impairment may jeopardize the patient's ability to safely and autonomously carry out an intended plan.

We provide two case examples of patients with RHD to illustrate how the speech-language pathologist (SLP) and others on the rehabilitation team consider the principle of respect for autonomy. The first case shows an issue that commonly occurs in the inpatient rehabilitation setting, whereas the second case describes some clinical dilemmas in the outpatient rehabilitation setting. When clinical issues arise, it is helpful to have a structure to guide the discussion and decision-making process, so that all parties can come to an acceptable resolution. For both cases, we use the model offered by Jonsen et al. ${ }^{1}$ They identified four categories of information that are relevant to a clinical ethics problem: (1) medical implications; (2) patient preferences; (3) quality of life; and (4) contextual features. The decision-making process involves organizing the facts around these four categories. In each case, we evaluate the components in relation to each other and with full consideration of the ethical principle of respect for autonomy, which falls within the category of "patient preferences."

\section{CASE 1: AN INPATIENT DILEMMA}

Approximately $75 \%$ of stroke survivors in the United States receive therapy in an inpatient rehabilitation facility (IRF) during the course of their recovery. ${ }^{18}$ The Centers for Medicare and Medicaid Services define an IRF as a freestanding rehabilitation hospital or unit that provides medical supervision and interdisciplinary intensive rehabilitation that includes at least 3 hours of therapy per day. ${ }^{19}$ The average length of stay in an IRF is 13.9 days for moderately impaired and 22.2 days for severely impaired stroke patients, with motor skills being a primary predictor of length of stay. ${ }^{20}$ In this setting, patient autonomy must be considered alongside multiple situational factors such as patient acuity and clinical presentation as well as particular aspects of the rehabilitation environment. The following case study illustrates one such instance that challenges the clinical team's ability to balance their respect for the patient's autonomy with what they perceive to be in his best interest.

$\mathrm{Mr} . \mathrm{M}$ is a 45-year-old right-handed man with a wife and two young children (aged 4 and 7). Mr. M works full-time as a regional salesman and his job is the primary source of income for his family. His wife works part-time as a school librarian and is the primary caregiver for their children. Ten days prior to his IRF admission, Mr. M suffered a right hemisphere thromboembolic stroke in the region of the middle cerebral artery which resulted in significant cognitive deficits including anosognosia, left unilateral neglect, impaired executive functions, flat affect, left hemiplegia, and a moderate oropharyngeal dysphagia.

According to the requirements of the $\mathrm{Pa}-$ tient Self-Determination Act, ${ }^{21}$ a patient has the right to make an informed refusal of life-sustaining interventions. During the admission process, in accordance with hospital policy informed by this legislation, the physician engages $\mathrm{Mr}$. $\mathrm{M}$ in a discussion of his right to complete an advance directive to outline provisions for medical decisions. Mrs. $\mathrm{M}$ is also present during this discussion. She states that Mr. M is the main decision 
maker in their family and that she would not want to make any decisions without him. Mrs. M encourages her husband to establish an advance directive so that his wishes will be "on the record." Mr. M states that he doesn't want to be "hooked up to machines." As the discussion continues, Mr. M has difficulty differentiating between mechanical respiratory support and the use of other non-life-sustaining machines and their relative implications for an advance directive. The physician becomes concerned about Mr. M's ability to make an autonomous informed decision due to his apparent cognitive impairments.

It is important to assess a patient's cognitive capacity to make choices that are truly autonomous following an acute illness. ${ }^{22} \mathrm{Mr}$. M's physician initiates a formal capacity assessment process by requesting a consult from the hospital's ethics team. In this hospital, the ethics team consists of bioethicists with both clinical and academic bioethical training as well as legal expertise. In accordance with the broad steps recommended by the National Center for Ethics in Healthcare, ${ }^{23}$ the ethics team clarifies the goal of the consultation request, reviews the medical chart, and requests clinical staff perspectives, including the SLP's assessment of Mr. M's cognitive status.

\section{Considerations}

As one of the few members of the inpatient rehabilitation interdisciplinary team tasked with direct assessment of cognitive abilities, the SLP's perspective on questions of decisional capacity has particular significance. However, the SLP's academic training may not have included explicit instruction on key concepts and requirements of decisional capacity. ${ }^{24}$ Furthermore, given the relatively short average length of stay in an IRF, SLPs are required to give input based on limited interactions with the patient, whereas guidelines for shared decision-making practices recommend extensive interactions. ${ }^{25}$

In this case, the request came at the beginning of Mr. M's stay. The SLP had completed the initial assessment but had not yet seen Mr. M for therapy. Additionally, the SLP had to distribute assessment time across multiple domains including dysphagia, and therefore had even less time to assess the patient's cognitive skills. Finally, the assessment occurred during the day when Mrs. M was working and unable to attend. This limited the SLP's ability to learn about Mr. M's premorbid level of cognitive functioning from an additional reliable source. However, the team wanted to make a determination in this matter as quickly as possible, so it was incumbent upon the SLP to make and communicate a clinical judgment based on the information available. For all members of the clinical team, it can be helpful to first examine the level of patient capacity required based on the relative risks involved (i.e., sliding-scale strategy). ${ }^{26}$ In this scenario, for example, the decision to outline an advance directive could have life and death consequences and therefore requires a high level of decisional capacity. A clinician may then organize the relevant details within a decisionmaking framework, such as the model suggested by Jonsen et al (as illustrated in Fig. 1). ${ }^{1}$

Although there are clearly many factors to consider, the medical indications include the details most relevant to the question of Mr. M's decisional capacity: impaired information processing and reasoning skills. The medical and bioethics literature has focused discussion of decisional capacity on a patient's ability to process information, make judgments, express a choice, and appreciate the consequences of his or her decision. ${ }^{17,27}$ Therefore, the SLP communicates that although he is able to express a choice, Mr. M's executive function deficits limit his ability to meet the other requirements of decisional capacity (i.e., to process and appreciate the implications of his choice and make an appropriate judgment).

\section{Resolution}

After gathering clinical staff perspectives, the ethics team meets with the patient and his wife in the evening. During the meeting, the ethics team describes the purpose of the interview and their role in the process. They then interview Mr. M directly. In line with the SLP's assessment, the ethics team finds that Mr. M is able to express consistent choices but breaks down when required to process complex information and demonstrate clear reasoning behind his 


\begin{tabular}{|c|c|}
\hline $\begin{array}{l}\text { Medical Indications } \\
\text { - Diagnosis: Right MCA stroke } \\
\text { - Unaware of deficits } \\
\text { - Moderate oropharyngeal dysphagia } \\
\text { - Frocessing and reasoning } \\
\text { - Fair prognosis }\end{array}$ & $\begin{array}{l}\text { Patient Preferences } \\
\text { - Patient states he does not want mechanical } \\
\text { respiratory support } \\
\text { - Patient and wife want to establish an } \\
\text { advance directive stating this preference }\end{array}$ \\
\hline $\begin{array}{l}\text { Quality of Life } \\
\text { - Safety issues } \\
\text { - Family dynamic: Wife generally defers to } \\
\text { patient for major decisions }\end{array}$ & $\begin{array}{l}\text { Contextual Features } \\
\text { - Predicted short length of IRF stay } \\
\text { limits opportunity to assess/build rapport } \\
\text { - SLP and psychologist perform primary } \\
\text { assessments of cognitive skills in IRF } \\
\text { - Wife cares for children at home during the } \\
\text { day and visits patient in the evening }\end{array}$ \\
\hline
\end{tabular}

Figure 1 Clinical decision-making model for the case of Mr. M. (Adapted from Jonsen et al. ${ }^{1}$ )

choices. The ethics team agrees Mr. M does not demonstrate the capacity necessary to complete the advance directive. The ethics team asks $\mathrm{Mr}$. M. who he would want to make decisions in his stead if he were unable to do so. He consistently chooses his wife but is adamant that there is no need at this time for her to be involved in any decision-making. In this way, the ethics team demonstrates respect for an important aspect of Mr. M's decisional autonomy. Although he continues to be unaware of the extent of his cognitive deficits, he does have the ability to delegate decision-making power to someone else.

Because his wife is able to observe her husband's difficulties during the interview, she understands when the ethics team explains their impressions from the interview and recommendation that Mr. M. defer to his wife as a surrogate decision maker at that time. Although he continues to deny needing her to make the decisions, Mr. M accepts the idea of having her represent his wishes as a "temporary plan." And in fact, state law where this case occurred (Illinois) dictates that once the physician documents that a patient lacks decisional capacity in the medical chart and the patient has been informed, the patient's spouse becomes the default surrogate. ${ }^{28}$ Importantly, to conclude their role in this case, the ethics team completes two more recommended steps following their meeting with $\mathrm{Mr}$. $\mathrm{M}$ and his wife. They synthesize the relevant information and their recommendations in the medical chart and communicate the outcomes directly to Mr. M's clinical team. This ensures that all team members are able to provide consistent communication around this order to Mr. M and his wife as they continue in their care.

\section{CASE 2: AN OUTPATIENT DILEMIMA}

Patients with RHD often present to outpatient therapy accompanied by unresolved or novel ethical dilemmas. Patients are learning to navigate the "real world" outside of a structured hospital setting for the first time with newly acquired impairments. Exploring facets of supervision, safety, and medical management, caregivers are tasked with providing care for a loved one who may not recognize the need for care. Likewise, patients are receiving therapy that may be less intensive in nature and increasingly constrained by insurance benefits. Patients at this stage may be navigating complex situations such as negotiating prolonged employment leave, ensuring short-term disability benefits, or managing medical bills, all alongside participation in therapy. Furthermore, the notion that outpatient therapy may be the last opportunity for direct service delivery places immense pressure on patients and families to attain desired outcomes prior to discharge. The following case study demonstrates some of the ethical considerations that arise, particularly in the context of autonomy, over the course of intensive outpatient therapy.

Ms. K, a single, 34-year-old second grade teacher, sustained a right hemisphere intracerebral hemorrhage due to suspected undiagnosed hypertension 6 weeks prior. At the time of discharge from an IRF, Ms. $\mathrm{K}$ continues to demonstrate mild-moderate short-term memory and executive functioning deficits in addition to a mild left visuospatial neglect. She has no residual physical impairments. The inpatient clinical team allows Ms. K to discharge home under the agreement that close friends will rotate 
providing 24-hour supervision. She transitions to working with a SLP and occupational therapist (OT) in an outpatient setting, receiving 2 hours of therapy per day, 2 days per week. During her initial evaluations, Ms. K states her goals for therapy are to live independently and return to work at discharge.

Within the first few weeks of therapy, it becomes apparent that Ms. K's cognitive deficits are hindering her ability to perform daily activities independently. Her OT reports Ms. K's medications were loose in her purse during a recent therapy session, which led Ms. K to admit she has occasionally neglected to take her blood pressure medication. She struggles to track information across sessions and demonstrates inflexibility within abstract reasoning tasks. She exhibits a low frustration tolerance when clinicians address breakdowns and often rationalizes errors (e.g., "This isn't something I need to do at work"). Ms. K indicates she has been in contact with her employer to coordinate a return to work, though she cannot recall substantive information from recent conversations. Furthermore, her friends begin to scale back on the 24hour supervision agreement with one friend expressing satisfaction with her "full recovery." Ms. K will reach her maximum allowable therapy visits in 6 weeks and conflicting views surrounding discharge goals emerge. Her situation is examined using the aforementioned model of Jonsen et al for clinical ethical decision-making ${ }^{1}$ (see Fig. 2).

\section{Considerations}

There are various ethical considerations unique to patients with RHD and the outpa- tient setting. First is the interpretation of Ms. K's capacity for autonomous decision-making at this stage in rehabilitation. Following criteria put forth by Appelbaum and Grisso, ${ }^{29}$ it is suggested Ms. $\mathrm{K}$ would have capacity as evidenced by her ability to communicate a preference, understand clinical recommendations, weigh risks and benefits of various outcomes, and appreciate the consequences of said outcomes through logical reasoning. However, these criteria may be weighted too heavily on Ms. K's decisional autonomy, while neglecting her executive autonomy. ${ }^{17}$ As introduced previously, while Ms. K's decisional autonomy (i.e., ability to make decisions or delegate that power to another) is intact, her executive autonomy (i.e., ability to effectively execute her autonomous decisions) continues to be impacted by her cognitive deficits. ${ }^{17}$ For example, Ms. K expressly wishes to live alone without supervision. However, she has not demonstrated means to manage her medications independently, putting her at risk for a second stroke. For Ms. K and others with milder RHD, conceptualizing the difference between making decisions and executing decisions may require a level of metacognitive awareness that is not yet accessible at this stage in recovery. Inability to grasp long-term implications of decisions made under the influence of impaired judgment or reasoning may have considerable and lasting effects.

As in the case of Ms. K, complex decisions such as evaluating work readiness also often occur at the outpatient level of care. The clinical team may recommend Ms. K delay a return to work until she has had adequate time to evaluate and address her acquired impairments. This

\begin{tabular}{|c|c|}
\hline $\begin{array}{l}\text { Medical Indications } \\
\text { - Right-bemisphere stroke with resulting } \\
\text { cognitive and visuospatial deficits } \\
\text { - Six weeks post-onset; slow but } \\
\text { measurable clinical improvements } \\
\text { - Candidate for restorative and } \\
\text { compensatory eognitive treatments }\end{array}$ & $\begin{array}{l}\text { Patient Preferences } \\
\text { - Lives alone without supervision } \\
\text { - Retum to work at discharge }\end{array}$ \\
\hline $\begin{array}{l}\text { Quality of Life } \\
\text { - Dispirited by clinical team's discharge } \\
\text { recommendations } \\
\text { - Feels the burden of supervision placed } \\
\text { on her friends has strained their } \\
\text { relationships } \\
\text { - Self-reliance and work are a major } \\
\text { element of her identity }\end{array}$ & $\begin{array}{l}\text { Contextual Features } \\
\text { - Inconsistent social support } \\
\text { - Outpatient therapy benefits conclude in } 6 \\
\text { weeks } \\
\text { - Employer has requested feedback about } \\
\text { continued need for medical leave } \\
\text { - Ms. K is her own source of income and } \\
\text { benefits }\end{array}$ \\
\hline
\end{tabular}

Figure 2 Clinical decision-making model for the case of Ms. K. (Adapted from Jonsen et al. ${ }^{1}$ ) 
recommendation by the clinical team, made in direct opposition to Ms. K's express wishes, may aim to preserve her long-term autonomy by opposing her short-term preferences. ${ }^{9}$ As Ms. K's awareness of her deficits emerges, gravitation toward a more collaborative decision-making paradigm should be employed. Such approaches could utilize sliding-scale capacity strategies ${ }^{26}$ (i.e., adopting a determination of capacity relevant to the inherent "riskiness" of the decision being made) or risk mitigation strategies $^{30}$ (i.e., recognizing that risk is inherent and attempting to balance it in the most equitable way possible).

A final consideration with the RHD population involves the therapeutic value derived from having opportunities to "restructure" conceptions about strengths and limitations through attempt, ${ }^{7}$ successful or unsuccessful. Ms. K may not comprehend clinical recommendations until she has had the opportunity to appraise her own skills outside of a therapeutic context. A therapeutic relationship in which a clinician allows the patient with RHD time and space to appreciate his or her own errors may lead to a greater recognition of breakdowns and subsequent self-awareness and self-efficacy. ${ }^{31}$ By maintaining open and supportive rapport, an individual with RHD may feel comfortable reaccessing services in the future as insight evolves.

\section{Resolution}

Ms. $\mathrm{K}$ agrees to a preliminary discharge meeting with the clinical team and two of her close friends. Various discharge dispositions are investigated, including clinical recommendations and patient preferences. Ms. $\mathrm{K}$ refuses the prescribed supervision arrangement, but compromises on a plan for friends to complete scheduled check-ins, both in-person and by phone. Although hesitant, Ms. K also agrees to meet with a vocational counselor to handle communications with her employer rather than navigate the process independently. Ms. K's therapy goals are not "met" according to standards imposed by either her or the clinical team; however, a conscious balance of respect for autonomy and preservation of best interest is considered.

\section{CONCLUSION}

Clinicians must often contend with ethical issues that arise during rehabilitation. Some concerns are unique to the rehabilitation setting such as ensuring, to the greatest extent possible, the patient's active participation in decisions about the focus and direction of treatment. When a patient has cognitive deficits, which typically occur in patients with RHD, these concerns may be exacerbated. In this article, we have provided two case examples of patients with RHD with sufficient language skills to express their choices, but cognitive deficits that affect their decision-making abilities. The patients differ in the severity of these cognitive deficits, as well as their specific medical indicators, preferences, situational context, and quality of life indicators, as outlined by the clinical decision-making model adapted from Jonsen et al. ${ }^{1}$ However, in both cases, the rehabilitation team strove to balance what they deemed to be in the best interest of the patient while continuing to respect the patient's autonomy.

The cases also illustrate that autonomy is not a fixed state, but is a "continuous and personally unique variable"15 that may change depending on the patient's situation. Autonomy can be affected by the person's cognitive impairments, or by the person's physical or social environment. Furthermore, patients may have the ability to make their own decisions for some situations, but not for others. It is therefore essential that the clinician consider the degree of both decisional autonomy and executive autonomy within the context of the specific role or activity. ${ }^{15}$

There are many ways in which clinicians can uphold autonomy in the context of rehabilitation. Blackburn and colleagues conducted a scoping review on this topic and identified four broad categories of clinician and team responses to patient autonomy in rehabilitation. ${ }^{8}$ Elements of these categories are present to varying degrees in Cases 1 and 2. First, supporting autonomy refers to efforts made to foster the patient's ability to make and enact choices that are consistent with their values and sense of self. This is accomplished by acknowledging the importance of relationships and including family members in discussions 
between the rehabilitation team and patient. Support is also accomplished through clear and consistent communications within the team and between the team, the patient, and family. Supporting autonomy is highlighted by Case 1. Second, promoting autonomy includes activities related to skill development, patient education, and enhancing participation, all designed to improve the patient's abilities to make decisions when autonomy has been diminished. Promoting autonomy is highlighted in Case 2. Third, respecting autonomy refers to respecting the goals that an individual wishes to pursue, the values they hold to be important, and the choices they wish to make. When choices are deemed to be risky, respecting autonomy includes collaboration, consensus, and problem solving with patients. Respecting autonomy is integral to both Cases 1 and 2 . Finally advocating for autonomy addresses broader social and institutional structures that limit autonomy. According to the authors, advocating for autonomy may include advocating for changes in the training of future health professionals so they are better able to respond to issues of patient autonomy within the rehabilitation setting. While advocating for autonomy is not addressed specifically by the case examples, it is interesting to consider the training that clinicians receive. Currently, graduate speech-language pathology programs require curricula that include identifying and treating cognitive-linguistic impairments while considering cultural factors in the process of evaluation and treatment planning. However, curriculum addressing issues related to decisional capacity and related ethical considerations is not currently required by ASHA accreditation standards. ${ }^{24}$ This is a knowledge gap that can lead to underinformed recommendations by the SLP and is, perhaps, an area for future advocacy.

\section{FINANCIAL DISCLOSURE}

Preparation of this manuscript was supported by the Coleman Foundation.

\section{CONFLICT OF INTEREST}

None declared.

\section{REFERENCES}

1. Jonsen AR, Siegler M, Winslade WJ. Clinical Ethics: A Practical Approach to Ethical Decisions in Clinical Medicine, 8th ed. New York, NY: McGraw-Hill Education; 2015

2. Tompkins CA. Rehabilitation for cognitive-communication disorders in right hemisphere brain damage. Arch Phys Med Rehabil 2012;93(01):S61-S69

3. Blake ML. The Right Hemisphere and Disorders of Cognition and Communication. San Diego, CA: Plural Publishing, Inc.; 2018

4. Stein MS, Kilbride C, Reynolds FA. What are the functional outcomes of right hemisphere stroke patients with or without hemi-inattention complications? A critical narrative review and suggestions for further research. Disabil Rehabil 2016;38 (04):315-328

5. Hewetson R, Cornwell P, Shum D. Social participation following right hemisphere stroke: Influence of a cognitive-communication disorder. Aphasiology 2018;32(02):164-182

6. Wainapel SF, Morice K. Ethical issues commonly managed during rehabilitation. PM\&R Knowledge NOW. 2014. Available at: https://now.aapmr.org/ ethical-issues-commonly-managed-during-rehabilitation. Accessed January 3, 2020

7. Hunt MR, Ells C. A patient-centered care ethics analysis model for rehabilitation. Am J Phys Med Rehabil 2013;92(09):818-827

8. Blackburn E, Durocher E, Feldman D, et al. Supporting, promoting, respecting and advocating: a scoping study of rehabilitation professionals' responses to patient autonomy. Can J Bioeth 2018;1(03):22-34

9. Sim J. Respect for autonomy: issues in neurological rehabilitation. Clin Rehabil 1998;12(01):3-10

10. Blackmer J. Ethical issues in rehabilitation medicine. Scand J Rehabil Med 2000;32(02):51-55

11. Kirschner KL, Stocking C, Wagner LB, Foye SJ, Siegler M. Ethical issues identified by rehabilitation clinicians. Arch Phys Med Rehabil 2001;82 (12, Suppl 2):S2-S8

12. Cherney LR. Ethical issues involving the right hemisphere stroke patient: to treat or not to treat? Top Stroke Rehabil 2006;13(04):47-53

13. Gillon R. Autonomy and the principle of respect for autonomy. Br Med J (Clin Res Ed) 1985;290 (6484):1806-1808

14. Hunt MR, Ells C. Partners towards autonomy: risky choices and relational autonomy in rehabilitation care. Disabil Rehabil 2011;33(11):961-967

15. Cardol M, De Jong BA, Ward CD. On autonomy and participation in rehabilitation. Disabil Rehabil 2002;24(18):970-974, discussion 975-1004

16. Collopy BJ. Autonomy in long term care: some crucial distinctions. Gerontologist 1988;28 (Suppl):10-17 
17. McCullough LB, Molinari V, Workman RH. Implications of impaired executive control functions for patient autonomy and surrogate decision making. J Clin Ethics 2001;12(04):397-405

18. Roger VL, Go AS, Lloyd-Jones DM, et al; American Heart Association Statistics Committee and Stroke Statistics Subcommittee. Executive summary: heart disease and stroke statistics-2012 update: a report from the American Heart Association. Circulation 2012;125(01):188-197

19. CMS.gov. Centers for Medicare and Medicaid Services. Inpatient Rehabilitation. Available at: https:// www.cms.gov/Medicare/Provider-Enrollment-andCertification/CertificationandCompliand/InpatientRehab. Accessed December 31, 2019

20. Camicia M, Wang H, DiVita M, Mix J, Niewczyk P. Length of stay at inpatient rehabilitation facility and stroke patient outcomes. Rehabil Nurs 2016;41 (02):78-90

21. Patient Self-Determination Act. Omnibus Budget Reconciliation Act of 1990. Public Law 1990(101508):4206

22. Horner J, Modayil M, Chapman LR, Dinh A. Consent, refusal, and waivers in patient-centered dysphagia care: Using law, ethics, and evidence to guide clinical practice. Am J Speech Lang Pathol 2016;25(04):453-469

23. Berkowitz K, Chanko B, Foglia M, Fox E, Powell T. Ethics Consultation: Responding to Ethics Questions in Health Care. 2nd ed. Veterans Health Administration. National Center for Ethics in Health Care; 2015
24. Council on Academic Accreditation. AudiologySpeech-Language Pathology-American SpeechLanguage-Hearing Association. Accreditation Standards for Graduate Programs. 2017; Available at: https://caa.asha.org/wp-content/uploads/Accreditation-Standards-for-Graduate-Programs. pdf. Accessed December 23, 2019

25. Barry MJ, Edgman-Levitan S. Shared decision making-pinnacle of patient-centered care. N Engl J Med 2012;366(09):780-781

26. Beauchamp TL, Childress JF. Respect for autonomy. In: Beauchamp T, Childress JF, eds. Principles of Biomedical Ethics. 8th ed. New York, NY: Oxford University Press; 2019:99-154

27. Fields LM, Calvert JD. Informed consent procedures with cognitively impaired patients: A review of ethics and best practices. Psychiatry Clin Neurosci $2015 ; 69(08): 462-471$

28. Illinois Department of Public Health (IDPH). Advanced Directives. Available at: http://www. dph.illinois.gov/topics-services/health-care-regulation/nursing-homes/advance-directives. Accessed December, 31, 2019

29. Appelbaum PS, Grisso T. Assessing patients' capacities to consent to treatment. N Engl J Med 1988;319(25):1635-1638

30. Young JM, Everett B. When patients choose to live at risk: What is an ethical approach to intervention? B C Med J. 2018;60(06):314-318

31. Toglia J, Kirk U. Understanding awareness deficits following brain injury. NeuroRehabilitation 2000; 15(01):57-70 